\title{
Technical note: Evaluation of a colorimetric point-of-care test for measuring urine ammonium concentration in periparturient dairy cattle
}

\author{
A. A. Megahed ${ }^{1,2}$ (-) and P. D. Constable ${ }^{1 *}$ (i) \\ ${ }^{1}$ Department of Veterinary Clinical Medicine, College of Veterinary Medicine, University of Illinois at Urbana-Champaign, Urbana 61802 \\ ${ }^{2}$ Department of Animal Medicine, Internal Medicine, Faculty of Veterinary Medicine, Benha University, Moshtohor-Toukh, Kalyobiya, 13736, Egypt
}

\begin{abstract}
Urine ammonium concentration $\left(\left[\mathrm{NH}_{4}^{+}\right]\right)$provides a clinically useful indicator of the magnitude of nutritionally induced systemic acidification in dairy cattle when urine $\mathrm{pH}<6.1$. The objective of this study was to evaluate the analytical performance of a low-cost pointof-care colorimetric test in measuring urine $\left[\mathrm{NH}_{4}{ }^{+}\right]$in dairy cattle consuming an acidogenic ration. A method comparison study was performed using 154 urine samples from 43 periparturient Holstein-Friesian cows. We compared urine $\left[\mathrm{NH}_{4}{ }^{+}\right]$measured by an indophenol blue colorimetric test (MColortest, Merck KGaA, Billerica, MA; test method) with levels measured by formaldehyde titration (reference method). Diagnostic performance was evaluated using Pearson correlation coefficient (r), Passing-Bablok regression, Bland-Altman plot, and binary logistic regression. Urine $\left[\mathrm{NH}_{4}{ }^{+}\right]$measured by the colorimetric test was strongly correlated $(\mathrm{r}=0.98)$ with urine $\left[\mathrm{NH}_{4}{ }^{+}\right]$measured by formaldehyde titration. Method comparison studies indicated that the colorimetric test provided acceptable test performance when urine $\left[\mathrm{NH}_{4}^{+}\right]<80 \mathrm{mmol} / \mathrm{L}$. Logistic regression analysis indicated that the area under the receiver operating characteristic curve for the colorimetric ammonium test was high at 0.985 when used to identify formaldehyde titration $\left[\mathrm{NH}_{4}^{+}\right]>10 \mathrm{mmol} / \mathrm{L}$, equivalent to urine $\mathrm{pH}$ $<6.1$. At the optimal cut point $\left(\left[\mathrm{NH}_{4}{ }^{+}\right]>11 \mathrm{mmol} / \mathrm{L}\right)$ for the colorimetric test, sensitivity $=0.94$, specificity $=0.97$, positive likelihood ratio $=27.6$, and $\kappa=0.89$, indicating excellent test performance. We conclude that the indophenol blue colorimetric test provided an accurate, low-cost, and practical on-farm test for measuring urine $\left[\mathrm{NH}_{4}{ }^{+}\right]$in diluted urine samples from dairy cattle consuming an acidogenic ration.
\end{abstract}

Key words: urine ammonium, acidosis, acidogenic diet, hypocalcemia

Received March 15, 2020.

Accepted May 1, 2020.

*Corresponding author: constabl@illinois.edu

\section{Technical Note}

Feeding an acidogenic ration during late gestation is a practical and effective approach for decreasing the incidence of periparturient hypocalcemia in dairy cattle (Constable et al., 2017; Lean et al., 2019). Ingestion of an acidogenic ration induces a strong ion (metabolic) acidosis that promotes aciduria, hypercalciuria, and increased $\mathrm{Ca}$ absorption from the gastrointestinal tract (Grünberg et al., 2011; Megahed et al., 2018; Constable et al., 2019). The marked hypercalciuria provides additional calcium that can be readily reabsorbed at parturition; however, it is important to minimize the development of excessive systemic acidification, as this results in decreased dry matter intake $(\mathrm{Hu}$ and Murphy, 2004). The urinary system excretes acid via 3 main pathways: (1) increased excretion of ammonium ions, resulting in increased urine ammonium concentration $\left(\left[\mathrm{NH}_{4}^{+}\right]\right)$; (2) increased proton excretion by $\mathrm{H}^{+}$$\mathrm{K}^{+}$-ATPase and $\mathrm{H}^{+}$-ATPase in tubular epithelial cells, resulting in decreased urine $\mathrm{pH}$ and increased titratable acidity (TA), with TA representing protons in the urine in the form of a weak acid; and (3) increased excretion and decreased reabsorption of phosphate, resulting in increased urine phosphate concentration and buffering capacity (Hamm and Simon, 1987; Lemann et al., 2003; Constable et al., 2019). A gradual increase in urinary ammonium excretion is the major method employed by vertebrates to address nutritionally induced systemic acidification (Hamm and Simon, 1987; Koeppen, 1998, 2009; Lemann et al., 2003).

Urinary excretion of acid has traditionally been quantified by calculating the net acid excretion (NAE) from the urinary $\left[\mathrm{NH}_{4}{ }^{+}\right]$, TA, and bicarbonate concentration $\left(\left[\mathrm{HCO}_{3}{ }^{-}\right]\right.$; Constable et al., 2009, 2019):

$$
\mathrm{NAE}=\left[\mathrm{NH}_{4}^{+}\right]+\mathrm{TA}-\left[\mathrm{HCO}_{3}^{-}\right]
$$

Net acid excretion is measured in the laboratory, and a practical on-farm method for measuring NAE is not currently available. We developed a physicochemical equation for urine that demonstrated urine $\mathrm{pH}$ is re- 
lated to NAE and $\left[\mathrm{NH}_{4}^{+}\right]$(Constable et al., 2009, 2019), as follows:

$$
\text { Urine } \mathrm{pH}=c+\log _{10}\left(\left[\mathrm{NH}_{4}^{+}\right]+\mathrm{TA}-\mathrm{NAE}\right),
$$

where $c \approx 6.1$ and $\mathrm{TA} \approx 0$ with an estimated value of $2.6 \mathrm{mmol} / \mathrm{L}$ in bovine urine [95\% confidence interval (CI), 0.6 to $4.6 \mathrm{mmol} / \mathrm{L}$; Constable et al., 2009]. Equation [2] confirmed widely held impressions that urine $\mathrm{pH}$ provides a clinically useful insight into the degree of systemic acidification in animals consuming acidogenic rations, in that low urine $\mathrm{pH}$ is associated with increased NAE and systemic metabolic acidosis, and therefore the possibility of over-acidification and systemic acidemia (Constable et al., 2009, 2019). We made an interesting and unexpected finding when Eq. [2] was applied to bovine urine, in that urine $\mathrm{pH}$ did not provide an accurate method to monitor the degree of systemic acidification in cattle consuming an acidogenic ration when urine $\mathrm{pH}<6.1$ (Constable et al., 2009, 2019). This was because urine $\left[\mathrm{NH}_{4}{ }^{+}\right]$can increase to more than $100 \mathrm{mmol} / \mathrm{L}$ when urine $\mathrm{pH}<$ 6.1 because $\Delta\left[\mathrm{NH}_{4}^{+}\right] \approx-\Delta \mathrm{NAE}$; as a result there is minimal change in the value of $\log _{10}\left(\left[\mathrm{NH}_{4}^{+}\right]+\mathrm{TA}-\right.$ NAE) in Eq. [2] and consequently minimal change in urine pH (Constable et al., 2009, 2019). Measurement of NAE, urine $\left[\mathrm{NH}_{4}^{+}\right]$, or venous blood gas analysis is therefore required to determine whether excessive systemic acidification is present in cattle consuming an acidogenic ration when urine $\mathrm{pH}<6.1$. Because the practical on-farm measurement of NAE is not possible, and on-farm blood gas analysis is costly and requires an anaerobically collected blood sample, measurement of urine $\left[\mathrm{NH}_{4}{ }^{+}\right]$provides the most practical method for accurately evaluating systemic acid-base status in cattle being fed an acidogenic ration when urine $\mathrm{pH}<6.1$.

Various methods are available for measuring $\left[\mathrm{NH}_{4}{ }^{+}\right]$in biological fluids, including titration, microdiffusion, ion selective electrode, and direct enzymatic methods $(\mathrm{Cu}-$ narro and Weiner, 1974; Huizenga et al., 1994). Urine $\left[\mathrm{NH}_{4}^{+}\right]$has been measured for many years using the titration method because the analytical method demonstrates the least variability (Cunarro and Weiner, 1974) and can be accomplished using the same equipment and urine sample as that for NAE. However, the titration method is not suitable for the on-farm measurement of urine $\left[\mathrm{NH}_{4}^{+}\right]$because it is time-consuming and requires a titrator and trained personnel. A colorimetric test (MColortest, Merck KGaA, Billerica, MA) is available for measuring $\left[\mathrm{NH}_{4}^{+}\right]$in water but is not currently approved for human or animal medical use in the United States. The test measures $\left[\mathrm{NH}_{4}{ }^{+}\right]$semiquantitatively by visual comparison of the test color with a color card within 10 to $15 \mathrm{~min}$. We hypothesized that the low cost (approximately $\$$ US1.50/test) and practicality of the colorimetric test make it potentially useful for the on-farm measurement of urine $\left[\mathrm{NH}_{4}{ }^{+}\right]$. The objective of this study was therefore to evaluate the analytical performance of the colorimetric test for measuring urine $\left[\mathrm{NH}_{4}^{+}\right]$in periparturient dairy cattle.

All methods were evaluated and approved by the Purdue Animal Care and Use Committee (West Lafayette, IN). The study reported here was part of a larger series of studies, and additional results have been published elsewhere (Megahed et al., 2018). Urine samples $(\mathrm{n}=154)$ were obtained by perineal stimulation and free-catch of voided urine from a convenience sample of 43 healthy periparturient Holstein-Friesian cows (13 primiparous, 30 multiparous) fed an acidogenic TMR during late gestation $(\mathrm{DCAD}=-17.5$ $\mathrm{mEq} / 100 \mathrm{~g}$ of $\mathrm{DM}$ ) and a standard lactating cow TMR $(\mathrm{DCAD}=+20.0 \mathrm{mEq} / 100 \mathrm{~g}$ of $\mathrm{DM})$ where DCAD $=$ $\left(\left[\mathrm{Na}^{+}\right]+\left[\mathrm{K}^{+}\right]\right)-\left(\left[\mathrm{Cl}^{-}\right]+\left[\mathrm{S}^{2-}\right]\right)$, as described elsewhere (Megahed et al., 2018). Urine samples were collected at approximately $0900 \mathrm{~h}$ on the last $3 \mathrm{~d}$ of gestation and the first day after calving. Samples were stored at $37^{\circ} \mathrm{C}$ and the $\mathrm{pH}$ measured within 15 min using a glasselectrode $\mathrm{pH}$ meter. Urine samples were then stored at $-20^{\circ} \mathrm{C}$, thawed within $2 \mathrm{mo}$, and homogeneously mixed by vortexing for $10 \mathrm{~s}$ immediately before measurement of NAE. Urine NAE and $\left[\mathrm{NH}_{4}^{+}\right]$were measured by titration, with all fluids at room temperature, as described elsewhere (Grünberg et al., 2011; Constable et al., 2019). Urine $\left[\mathrm{NH}_{4}^{+}\right]$was also measured using the MColortest point-of-care colorimetric test (Merck) after thawing urine samples stored for up to $5 \mathrm{yr}$ at $-20^{\circ} \mathrm{C}$. Urine $\left[\mathrm{NH}_{4}^{+}\right]$is stable for at least $15 \mathrm{yr}$ when samples are stored at $-20^{\circ} \mathrm{C}$ (Remer et al., 2014). Thawed urine samples were vortexed and diluted 1:100 with distilled water to enable accurate measurement of urine $\left[\mathrm{NH}_{4}{ }^{+}\right]$. The majority of urine ammonium nitrogen $\left(\mathrm{NH}_{4}{ }^{+}-\mathrm{N}\right)$ over the physiological range for urine $\mathrm{pH}$ occurs in the form of ammonium ions $\left(\mathrm{NH}_{4}^{+}\right)$with a small amount existing as ammonia (Weiner and Verlander, 2017). The test principle was that $\mathrm{NH}_{4}{ }^{+}-\mathrm{N}$ exists almost entirely as ammonia in strongly alkaline solutions $(\mathrm{pH}>10)$, with ammonia reacting with a chlorinating agent to form monochloramine, which in turn reacts with thymol to form a blue indophenol derivative. Because of the intrinsic yellow coloration of the reagent blank, the final solution color was yellow-green to green, depending on the $\left[\mathrm{NH}_{4}^{+}\right]$.

Each urine sample was measured using the colorimetric test in duplicate and the average of the 2 measurements used as the actual value. Two test tubes provided in the colorimetric test box were rinsed several times 
with the diluted urine sample. Five milliliters of diluted urine were added to measurement and blank tubes using a syringe provided in the test box. Twelve drops of reagent $\mathrm{NH}_{4}^{+}-1$ (sodium hydroxide) were then added to the measurement tube and mixed thoroughly. One level microspoon of reagent $\mathrm{NH}_{4}{ }^{+}-2$ (chlorinating agent) was added to the mixture in the measurement tube. The measurement tube was shaken vigorously until the reagent was completely dissolved. The tube was allowed to stand for $5 \mathrm{~min}$, and then 4 drops of reagent $\mathrm{NH}_{4}{ }^{+}-3$ (2-propanol thymol) were added and mixed thoroughly. The measurement and blank tubes were inserted into the sliding comparator and placed on the color card for $7 \mathrm{~min}$. The comparator was slid along the color scale until the closest possible color match was achieved between the 2 open tubes when viewed from above (Figure 1). The measurement range of the test was 0.2, $0.4,0.6,1.0,2.0,3.0$, and $5.0 \mathrm{mg} / \mathrm{L}_{\text {of }} \mathrm{NH}_{4}{ }^{+}$, equivalent to $1.1,2.2,3.3,5.4,10.9,16.3$, and $27.2 \mathrm{mmol} / \mathrm{L}$ in the diluted urine sample. The midpoint of the difference in values was recorded when the measurement tube color was intermediate between 2 colors on the color card. If the color of the measurement solution was equal to or more intense than the darkest color on the scale, the measurement was repeated using a higher dilution factor, typically $1: 200$ or 1:400, until an $\left[\mathrm{NH}_{4}{ }^{+}\right]$value of $<5 \mathrm{mg} / \mathrm{L}(<27.2 \mathrm{mmol} / \mathrm{L})$ was obtained. Measured values were corrected for the dilution factor.

Statistical analyses were performed using SAS 9.4 (SAS Institute Inc., Cary, NC) and MedCalc Statistical Software, version 19.1.3 (MedCalc Software bvba, Ostend, Belgium); $P<0.05$ was considered significant. Within-day repeatability was evaluated by calculating the coefficient of variation (CV) from 10 consecutive analyses of a purposively collected sample on the same day. The Pearson correlation coefficient (r) was calculated to characterize the linear relationship between urine $\left[\mathrm{NH}_{4}^{+}\right]$measured by the POC colorimetric test and titration. Only the first urine sample analyzed from each cow was used for correlation analysis, to meet the independence of samples assumption.

The analytical performance of the colorimetric test was assessed by comparison to the allowable total error as reference $\left[\mathrm{NH}_{4}^{+}\right] \pm 20 \%$ (Harr et al., 2013). Passing-Bablok regression was used to evaluate the linear relationship between urine $\left[\mathrm{NH}_{4}^{+}\right]$measured by the colorimetric test and reference method. For Passing-Bablok regression, the intercept value reflects the constant error, and the slope reflects the proportional error. A Bland-Altman difference plot was used to assess the agreement between the colorimetric test and reference method. This statistical analysis method ignored the inclusion of 2 to 4 urine samples per cow, as the number of samples per cow was much lower than the total number of cows $(n=43)$. The mean bias of the Bland-Altman plot and associated 95\% CI were calculated over the range of measured values. Upper and lower limits of agreement in the Bland-Altman plot were calculated from the mean bias $\pm 1.96 \times$ standard deviation. The colorimetric test and reference method were considered suitable for measuring urine $\left[\mathrm{NH}_{4}{ }^{+}\right]$if the $95 \%$ CI for the limits of agreement $<$ allowable total error (Chhapola et al., 2015).

Binary logistic regression was used to characterize the relationship between urine $\left[\mathrm{NH}_{4}^{+}\right]$measured by formaldehyde titration $\left(1=\right.$ urine $\left[\mathrm{NH}_{4}^{+}\right]>10 \mathrm{mmol} / \mathrm{L} ; 0=$ urine $\left.\left[\mathrm{NH}_{4}^{+}\right] \leq 10 \mathrm{mmol} / \mathrm{L}\right)$ and the indophenol blue colorimetric test, as described elsewhere (Constable et al., 2019). A cut point of $>10 \mathrm{mmol} / \mathrm{L}$ for the reference method was selected because urine $\left[\mathrm{NH}_{4}{ }^{+}\right]$values $>10$ $\mathrm{mmol} / \mathrm{L}$ provide a much more accurate indicator of the magnitude of nutritionally induced systemic acidification in dairy cattle than urine $\mathrm{pH}<6.1$ (Constable et al., 2019). A receiver operating characteristic (ROC) curve was constructed, and the area under the ROC curve was calculated as a global index of the performance of the colorimetric test. Sensitivity (Se) and specificity (Sp) were calculated at the optimal cut point of the ROC, determined by the Youden index, which indicated the reference method $\left[\mathrm{NH}_{4}{ }^{+}\right]>10 \mathrm{mmol} / \mathrm{L}$. The positive likelihood ratio $(+\mathbf{L R})$ was calculated as: $+\mathrm{LR}=\mathrm{Se} /$ $(1-\mathrm{Sp})$, and the kappa coefficient $(\kappa)$ was calculated at the optimal cut point to further characterize the level of agreement between the tests.

The mean within-day $\mathrm{CV}$ for urine $\left[\mathrm{NH}_{4}^{+}\right]$values of $4.0,25.5$, and $53.0 \mathrm{mmol} / \mathrm{L}$ measured using the colorimetric test were $11.8,8.7$, and $15.0 \%$, respectively. An excellent correlation existed between urine $\left[\mathrm{NH}_{4}^{+}\right]$ measured by the colorimetric test and the reference method $(\mathrm{r}=0.98 ; P<0.0001 ; \mathrm{n}=43)$. Passing-Bablok regression comparing the colorimetric test to the reference method revealed the presence of proportional bias (slope $=0.935 ; 95 \%$ CI: 0.905 to 0.978 ) but absence of constant bias (intercept $=-0.2 \mathrm{mmol} / \mathrm{L} ; 95 \% \mathrm{CI}$ : -0.7 to 0.1 ; Figure $2 \mathrm{~A}$ ). The bias estimate from the accompanying Bland-Altman plot indicated that the colorimetric test measured urine $\left[\mathrm{NH}_{4}{ }^{+}\right] 1.7 \mathrm{mmol} / \mathrm{L}$ lower than the reference method (95\% CI: -2.2 to -1.3 $\mathrm{mmol} / \mathrm{L}$; Figure 2B). Inspection of the Bland-Altman plot indicated that proportional error was present, based on an estimated slope value for linear regression of differences against mean values (slope $=-0.10 ; P<$ 0.0001); however, constant error was not present, based on the nonsignificant value for the intercept $(-0.2, P=$ $0.61)$. It should be noted that the estimated bias $(-1.7$ $\mathrm{mmol} / \mathrm{L}$ ) from the Bland-Altman plot is not an accurate measure of constant bias when proportional bias is present, as in this case. Taken together, the Passing- 
Bablock regression and Bland-Altman plots indicated the presence of proportional bias of $-6.5 \%$, with $95 \%$ CI -2.2 to $-9.5 \%$, and absence of constant bias. The colorimetric test therefore provided acceptable test per- formance over the range of values for urine $\left[\mathrm{NH}_{4}^{+}\right]$of 0 to $80 \mathrm{mmol} / \mathrm{L}$ because $-9.5 \%$ was $< \pm 20 \%$.

Logistic regression analysis indicated that the area under the ROC curve for the colorimetric test was very

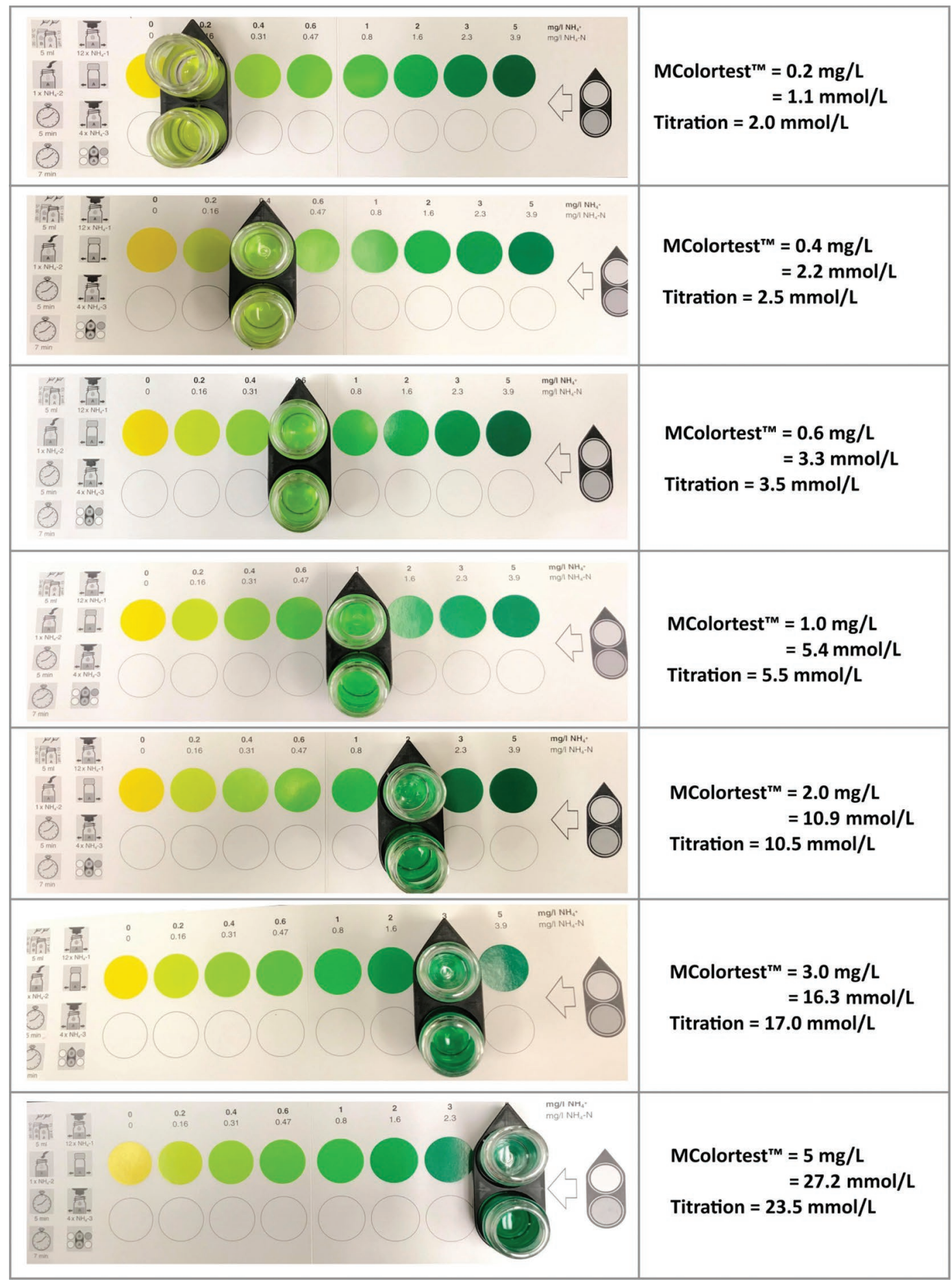

Figure 1. Ammonium concentration measurements $\left(\left[\mathrm{NH}_{4}^{+}\right]\right)$using the MColortest point-of-care colorimetric test (Merck KGaA, Billerica, MA) with color card and sliding comparator in 7 urine samples from dairy cattle consuming an acidogenic ration in last gestation. 
high, at 0.985 (95\% CI: 0.972 to 0.999). At the optimal cut point $(>11 \mathrm{mmol} / \mathrm{L})$ for the colorimetric test, Se $=0.94$ (95\% CI: 0.87 to 0.98$), \mathrm{Sp}=0.97$ (95\% CI: 0.88 to 1.00$)$, $+\mathrm{LR}=27.6$ (95\% CI: 7.1 to 108.0 ), and $\kappa=0.89$ (95\% CI: 0.82 to 0.96$)$. Collectively, these test performance indicators confirmed our hypothesis
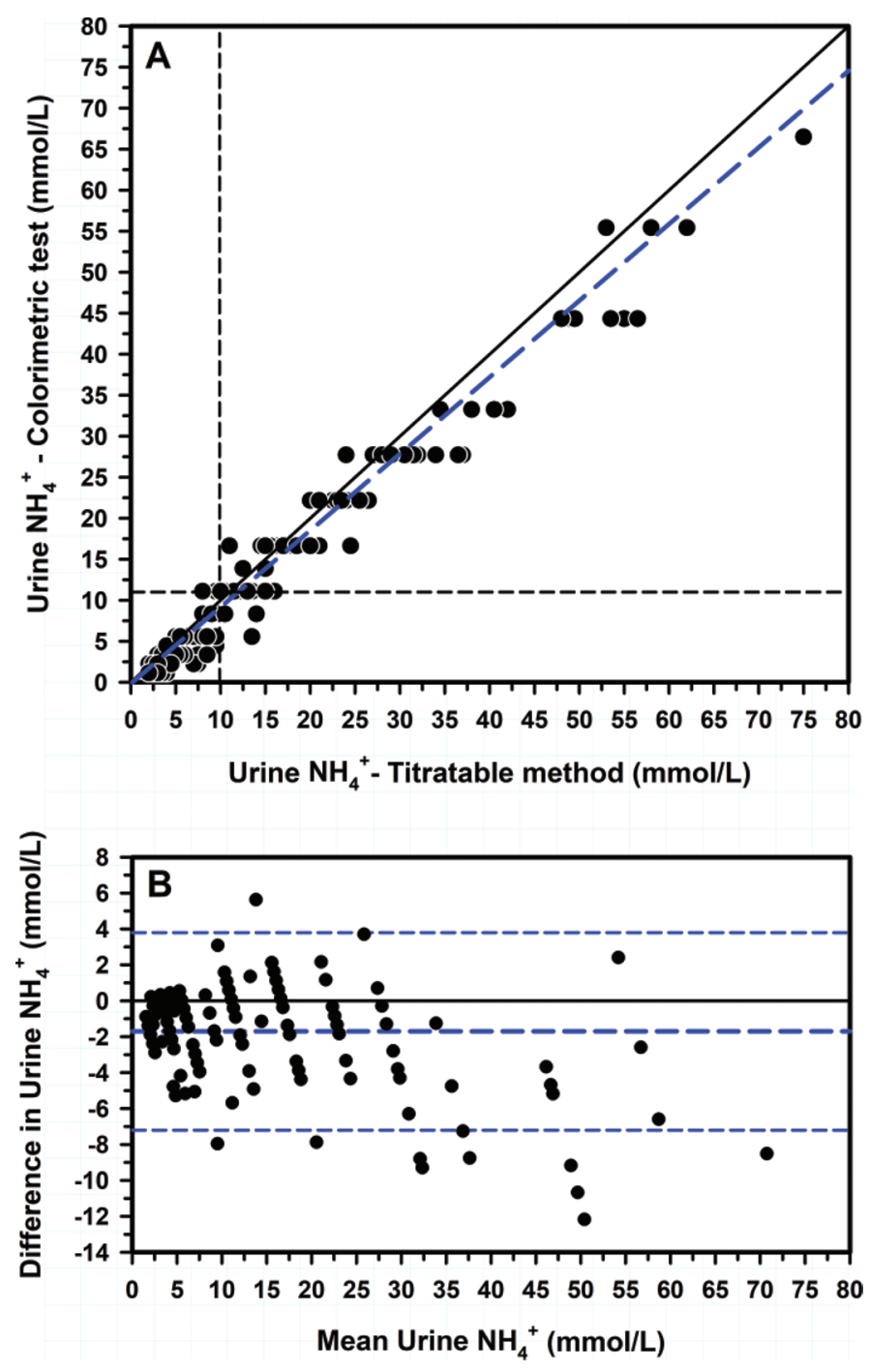

Figure 2. (A) Scatterplot of the relationship between the urine ammonium concentration $\left(\left[\mathrm{NH}_{4}^{+}\right]\right)$measured by the MColortest pointof-care colorimetric test (Merck KGaA, Billerica, MA) and by titration as the reference method for 154 urine samples from 43 healthy periparturient Holstein-Friesian cows (13 primiparous, 30 multiparous). The diagonal solid black line is the line of identity, and the long-dashed blue line is the line of best fit from Passing-Bablok regression; the analysis indicates the presence of proportional, but not constant, bias. (B) Bland-Altman difference plot. The horizontal long-dashed blue line is the mean bias $(-1.7 \mathrm{mmol} / \mathrm{L})$, and the horizontal short-dashed blue lines reflect the $95 \%$ limits of agreement, which is equivalent to the range of differences that contains $95 \%$ of future measurements. The scatterplot indicates the presence of proportional bias in that data points are not distributed equally above and below the mean bias line. that the colorimetric test was suitable for identifying urine $\left[\mathrm{NH}_{4}{ }^{+}\right]>10 \mathrm{mmol} / \mathrm{L}$ as measured by the reference method, based on the area under the ROC curve, Se, and $\mathrm{Sp}>0.90,+\mathrm{LR}>10$, and $\kappa>0.8$ (Constable et al., 2019).

One of the main goals for our laboratory has been to develop a practical, low-cost, and accurate on-farm test for identifying nutritionally induced systemic acidosis in periparturient dairy cattle consuming an acidogenic diet. A limitation of this study was that the degree of systemic acidosis was not evaluated using blood gas analysis; however, acidemia was very likely to be present in some cows because blood $\mathrm{pH}$ is decreased in dairy cattle by $\geq 0.02$ when urine $\left[\mathrm{NH}_{4}^{+}\right]>20 \mathrm{mmol} / \mathrm{L}$ (Gelfert et al., 2010). To the best of our knowledge, this was the first study to evaluate the analytical performance of a colorimetric test for measuring urine $\left[\mathrm{NH}_{4}{ }^{+}\right]$. Urine dilution was used for the indophenol blue colorimetric test because of the presence of inhibiting factors, such as nonprotein nitrogen substances (Okuda et al., 1965), and to overcome the narrow measurement range of the colorimetric test. Urine dilution of 1:100 used in this study showed the operational validity of the colorimetric test for measuring urine $\left[\mathrm{NH}_{4}^{+}\right]$in dairy cattle. The MColortest test showed a relatively high CV that was most likely due to inconsistent interpretation of color changes by the observer. However, the measurement resolution was adequate for clinical use, based on our published study (Constable et al., 2019). Colorimetric tests using Nessler's reagent [a solution of potassium tetraiodomercurate(II) in potassium hydroxide] to form a yellow-brown compound are available to measure urine $\left[\mathrm{NH}_{4}^{+}\right]$; compared with the indophenol blue colorimetric test, the Nessler reagent test has the advantage of not requiring dilution and a measurement range for $\left[\mathrm{NH}_{4}{ }^{+}\right]$of 0.6 to $22.2 \mathrm{mmol} / \mathrm{L}$ for a 5 -mL urine sample. The validity of the Nessler colorimetric test was not evaluated in this study because of the small numbers of stored urine samples $>5 \mathrm{~mL}$ in volume.

We conclude that the indophenol blue colorimetric test provides an accurate low-cost on-farm test for measuring urine $\left[\mathrm{NH}_{4}^{+}\right]$in late-gestation dairy cattle. Based on the results of this study and our previous studies (Constable et al., 2009, 2019), a practical low-cost method for evaluating the degree of systemic acidification in cattle fed an acidogenic ration is to monitor urine $\mathrm{pH}$ as an initial screening test using $\mathrm{pH}$ indicator papers to estimate urine $\mathrm{pH}$ in free-catch urine samples (Constable et al., 2019). In urine samples with $\mathrm{pH}$ $<6.1$, urine $\left[\mathrm{NH}_{4}^{+}\right]$should then be measured using an indophenol blue colorimetric test or similar validated tests. Moderate $(20 \mathrm{mmol} / \mathrm{L})$ to high $(200 \mathrm{mmol} / \mathrm{L})$ values for urine $\left[\mathrm{NH}_{4}^{+}\right]$should raise concern about the presence of over-acidification. 


\section{ACKNOWLEDGMENTS}

Funding for this study was provided, in part, by a Government Mission Program grant from the Cultural and Educational Bureau, the Embassy of the Arab Republic of Egypt (A. A. Megahed). The authors have not stated any conflicts of interest.

\section{REFERENCES}

Chhapola, V., S. K. Kanwal, and R. Brar. 2015. Reporting standards for Bland-Altman agreement analysis in laboratory research: A cross-sectional survey of current practice. Ann. Clin. Biochem. 52:382-386. https://doi.org/10.1177/0004563214553438.

Constable, P. D., C. C. Gelfert, M. Furll, R. Staufenbiel, and H. Stampfli. 2009. Application of strong ion difference theory to urine and the relationship between urine $\mathrm{pH}$ and net acid excretion in cattle. Am. J. Vet. Res. 70:915-925. https://doi.org/10.2460/ajvr .70.7.915.

Constable, P. D., K. W. Hinchcliff, S. H. Done, and W. Grünberg. 2017. Pages 1675-1693 in Veterinary Medicine - A Textbook of the Diseases of Cattle, Horses, Sheep, Pigs and Goats. 11th ed. Elsevier Health Sciences, St. Louis, MO.

Constable, P. D., A. A. Megahed, and M. W. Hiew. 2019. Measurement of urine $\mathrm{pH}$ and net acid excretion and their association with urine calcium excretion in periparturient dairy cows. J. Dairy Sci. 102:11370-11383. https://doi.org/10.3168/jds.2019-16805.

Cunarro, J. A., and M. W. Weiner. 1974. A comparison of methods for measuring urinary ammonium. Kidney Int. 5:303-305. https://doi .org/10.1038/ki.1974.41.

Gelfert, C. C., L. M. Loeffler, S. Frömer, M. Engel, K. Männer, and R. Staufenbiel. 2010. Comparison of the impact of different anionic salts on the acid-base status and calcium metabolism in non-lactating, non-pregnant dairy cows. Vet. J. 185:305-309. https://doi .org/10.1016/j.tvjl.2009.06.013.

Grünberg, W., S. S. Donkin, and P. D. Constable. 2011. Periparturient effects of feeding a low dietary cation-anion difference diet on acidbase, calcium, and phosphorus homeostasis and on intravenous glucose tolerance test in high-producing dairy cows. J. Dairy Sci. 94:727-745. https://doi.org/10.3168/jds.2010-3230.

Hamm, L. L., and E. E. Simon. 1987. Roles and mechanisms of urinary buffer excretion. Am. J. Physiol. 253:F595-F605. https://doi.org/ 10.1152/ajprenal.1987.253.4.F595.
Harr, K. E., B. Flatland, M. Nabity, and K. P. Freeman. 2013. ASVCP guidelines: Allowable total error guidelines for biochemistry. Vet. Clin. Pathol. 42:424-436. https://doi.org/10.1111/vcp.12101.

Hu, W., and M. R. Murphy. 2004. Dietary cation-anion difference effects on performance and acid-base status of lactating dairy cows: A meta-analysis. J. Dairy Sci. 87:2222-2229. https://doi.org/10 .3168/jds.S0022-0302(04)70042-9.

Huizenga, J. R., A. Tangerman, and C. H. Gips. 1994. Determination of ammonia in biological fluids. Ann. Clin. Biochem. 31:529-543. https://doi.org/10.1177/000456329403100602.

Koeppen, B. M. 1998. Renal regulation of acid-base balance. Adv. Physiol. Educ. 275:S132-S141. https://doi.org/10.1152/advances .1998.275.6.S132.

Koeppen, B. M. 2009. The kidney and acid-base regulation. 33:275281. https://doi.org/10.1152/advan.00054.2009.

Lean, I. J., J. E. P. Santos, E. Block, and H. M. Golder. 2019. Effects of prepartum dietary cation-anion difference intake on production and health of dairy cows: A meta-analysis. J. Dairy Sci. 102:21032133. https://doi.org/10.3168/jds.2018-14769.

Lemann, J. Jr., D. A. Bushinsky, and L. L. Hamm. 2003. Bone buffering of acid and base in humans. Am. J. Physiol. Renal Physiol. 285:F811-F832. https://doi.org/10.1152/ajprenal.00115.2003.

Megahed, A. A., M. W. Hiew, S. A. El Badawy, and P. D. Constable. 2018. Plasma calcium concentrations are decreased at least 9 hours before parturition in multiparous Holstein-Friesian cattle in a herd fed an acidogenic diet during late gestation. J. Dairy Sci. 101:1365-1378. https://doi.org/10.3168/jds.2017-13376.

Okuda, H., S. Fujii, and Y. Kawashima. 1965. A direct colorimetric determination of blood ammonia. Tokushima J. Exp. Med. 12:11-23.

Remer, T., G. Montenegro-Bethancourt, and L. Shi. 2014. Long-term urine biobanking: Storage stability of clinical chemical parameters under moderate freezing conditions without use of preservatives. Clin. Biochem. 47:307-311. https://doi.org/10.1016/j.clinbiochem .2014.09.009.

Weiner, I. D., and J. W. Verlander. 2017. Ammonia transporters and their role in acid-base balance. Physiol. Rev. 97:465-494. https:// doi.org/10.1152/physrev.00011.2016.

\section{ORCIDS}

A. A. Megahed (1) https://orcid.org/0000-0003-2006-8873

P. D. Constable @ https://orcid.org/0000-0003-1929-2106 